\title{
MOVIMENTOS MIGRATÓRIOS NO MUNICÍPIO DE CATOLÉ DO ROCHA - PB
}

\author{
MOVIMIENTOS MIGRATORIOS EN CONDADO CATOLÉ DO ROCHA - PB
}

\section{MIGRATION MOVEMENTS IN THE CITY OF CATOLÉ DO ROCHA - PB}

\author{
Mário Leno Martins VÉRAS ${ }^{1}$ \\ Alexandro de Figueiredo ANDRADE ${ }^{2}$ \\ Lunara de Sousa ALVES ${ }^{3}$ \\ Toni Halan da Silva IRINEU ${ }^{4}$ \\ Francineide Pereira SILVA ${ }^{5}$
}

RESUMO: A desruralização é um fenômeno comum no nordeste do Brasil, muitos nordestinos deslocam para as cidades - lugar atrativo e moderno - em busca de emprego, mas sem sucesso, retornam a cidade-natal. Para muitos destes migrantes a estrutura rural deixa a desejar no que se diz respeito à saúde, trabalho, políticas públicas e gestão de água, uma vez que, atrai estes indivíduos que procuram melhores condições de vida. O objetivo primordial dessa pesquisa é de verificar quais motivos fazem com que a população rural desloque para acidade, como também verificar a remição entre escassez hídrica e êxodo rural no município de Catolé do Rocha - PB. A pesquisa segue modelos metodológicos quantitativos e qualitativos, onde foram entrevistadas 37 famílias na zona rural a fim de diagnosticar os fatores que ocasionam o êxodo rural no município. No sitio cajueiro como os outros sítios apresentam um déficit de água, onde muitas famílias carentes precisam abastecer as cisternas por carro-pipa, neste caso, comprometendo o orçamento familiar. É preciso, sobretudo, estabelecer condições do homem do campo viver no meio rural, para que o mesmo não precise se deslocar para a cidade.

Palavras-chave: Migração; Êxodo rural; Ruralização.

RESUMEN: La desruralización es un fenómeno común en el noreste de Brasil, muchos de movimiento del noreste a las ciudades - atractivo, lugar moderno - en busca de empleo, pero sin éxito, volver a la ciudad natal. Para muchos de estos inmigrantes en la estructura rural es débil en cuanto a la salud, el trabajo, las políticas públicas y la gestión del agua, ya que atrae a estas personas que buscan mejores condiciones de vida. El objetivo principal de esta investigación es comprobar qué razones hacen que el desplazamiento de la población rural a la Capacidad, así como verificar la redención entre la escasez de agua y el éxodo rural en

\footnotetext{
${ }^{1}$ Mestrando em agronomia, Universidade Federal da Paraíba - UFPB/Campus II - Areia - Paraíba - Brasil. mario.deus1992@bol.com.br

${ }^{2}$ Graduado em Ciências Agrárias, Universidade Estadual da Paraíba - UEPB/Campus IV - CEP 58884-000 Catolé do Rocha - Paraíba - Brasil. afigueiredoandrade@bol.com.br

${ }^{3}$ Graduada em Ciências Agrárias, Universidade Estadual da Paraíba - UEPB/Campus IV - CEP 58884-000 Catolé do Rocha - Paraíba - Brasil. lunara_alvesuepb@hotmail.com

${ }^{4}$ Universidade Federal da Paraíba - UFPB. tonnysilva_oliveira@ hotmail.com

${ }^{5}$ Universidade Estadual da Paraíba - UEPB - rochafranci1 @ hotmail.com
} 
municipio Catolé do Rocha - PB. La investigación sigue modelos metodológicos cuantitativos y cualitativos, se entrevistó a 37 familias en el campo con el fin de diagnosticar los factores que provocan el éxodo rural en la ciudad. En el sitio de anacardo al igual que otros sitios tienen un déficit de agua, donde muchas familias pobres necesitan para abastecer los tanques, vagón cisterna, en este caso, lo que afecta el presupuesto familiar. Debemos, sobre todo, establecer las condiciones de campo de los hombres viven en las zonas rurales, por lo que no es necesario ir a la ciudad.

Palabras chaves: Migración; El éxodo rural; Ruralización.

\begin{abstract}
The deruralization is a common phenomenon in northeastern Brazil, many northeastern moving to cities - place attractive and modern - in search of employment, but without success, return to hometown. For many of these migrants to rural infrastructure is weak as it relates to health, work, public policy and water management, since it attracts those individuals seeking a better life. The primary objective of this research is to ascertain the reasons which make rural people move to acity, as also check redemption between water scarcity and rural exodus in the municipality of Catolé do Rocha - PB. The research follows quantitative and qualitative methodological models, were interviewed 37 families in the countryside in order to diagnose the factors that cause the rural exodus in the municipality. In cashew site like other sites showed a deficit of water, where many poor families need fuel tanks by tanker car, in this case, jeopardizing the family budget. It is necessary, above all, establish conditions of the rural living in rural areas, so that it does not need to move to the city.
\end{abstract}

Keywords: Migration; Rural exodus; Ruralization.

\title{
INTRODUÇÃO
}

$\mathrm{Na}$ contemporaneidade a transformação que tem ocorrido em escala nacional tem mostrado que o êxodo rural não deixou ainda de atingir as populações rurais, em especial do nordeste, desse modo, as políticas públicas de incentivo a permanência no campo mostraramse como tentativas solucionativas, contudo, as mesmas não têm conseguido dinamizar a estadia do homem no meio rural, neste caso, ocasionando a migração para os centros urbanos. Para muitos destes migrantes a estrutura rural deixa a desejar no que se diz respeito à saúde, trabalho, políticas públicas e gestão de água, uma vez que, atrai estes indivíduos que procuram melhores condições de vida. Como ratifica Alves (2006):

Com o passar do tempo, a família percebe a importância de dar melhor educação para os filhos e de acesso a infraestrutura social que a cidade oferece, além do diferencial dos salários. Obtém informações dos que já migraram. Descobre o favorecimento que o governo prevê a quem se urbaniza, ao qual o rurícola não tem acesso.

A desruralização é um fenômeno comum no nordeste do Brasil, muitos nordestinos deslocam para as cidades - lugar atrativo e moderno - em busca de emprego, mas sem 
sucesso, retornam a cidade-natal. Conforme Menezes (2008) o caso do Nordeste o fator que causou as migrações rurais foram as constantes secas, como também à atração das cidades.

Já Araújo (2002) ressalta que os pesquisadores do Centro de Estudos Migratórios (CEM) negam que o fator é causado pela seca e sim pela terra e que o estado teve sua atuação referente à seca:

No nordeste, tradicional área de expulsão, o que ocasiona o êxodo rural não é tanto a seca, mas, sobretudo a cerca, (grifos do original) (...) os projetos governamentais de combate a seca acabam desalojando maior número de famílias que os que conseguem se fixar na terra (CEM, 1986, p.31 apud ARAÚJO, 2002).

Ainda segundo esses autores, se o êxodo é ocasionado pela expropriação dos pequenos produtores á terra isto se deve ao "processo de transformação dos produtores diretos em trabalhadores livres, verificado no aumento dos trabalhadores assalariados" (CEM, 1986,p.47 apud ARAÚJO, 2002).

Outro motivo que faz com que esses movimentos se tornem constantes é a falta de políticas públicas voltadas para o campo, a exemplo do P1MC (Programa Um Milhão de Cisternas rurais), Pronaf (Programa Nacional de Fortalecimento da Agricultura Familiar) entre outros. A assistência ao agricultor é primordial para o fortalecimento e fixação na sua região, como relata Sousa (2011):

As políticas públicas são de suma importância para o movimento emergente de uma determinada região. A falta dessas politicas dificulta a fixação do homem no seu meio, levando-os assim ao êxodo rural e a elevação das populações das grandes cidades, acentuando com isso o problema social urbano, problema esse que poderia ser minimizado se houvesse efetivamente a presença dessas políticas a atender a demanda do homem do campo, pois o mesmo não perderiao prazer de viver em sua região e tampouco sairia em busca de melhores condições de vida.

A zona rural muitas vezes apresenta um déficit de educação, onde a maioria das escolas não tem boas condições dos alunos estudarem e em consequência disso é que a maior parte dos filhos dos agricultores não conseguem chegar ao mercado de trabalho. Sendo assim, o deslocamento para as cidades uma opção da população rural. Há ainda a falta de trabalho no meio rural, as profissões mais vistas são agricultores, pescadores, aposentados, dona de casa e pecuarista, e isso deixa claro que favorece o movimento. Como Cita Brito e Ribeiro (2010):

O trabalho é um fator de grande motivação para se migrar. É considerado possibilidade de prosperação. Noentanto, nos grandes centros urbanos, o numero de vagas é restrito e exige qualificação, o que contribui para a não integração no mercado de trabalho.

A ruralidade presente em populações urbanizadas de Catolé do Rocha é um fenômeno que com o passar do tempo tem crescido, a maioria residente na periferia da cidade mostra que a escassez hídrica no meio rural foi um fator que ocasionou essa migração. 
O objetivo primordial dessa pesquisa é de verificar quais motivos fazem com que a população rural desloque para acidade, como também verificar a remição entre escassez hídrica e êxodo rural no município de Catolé do Rocha.

É fato que quando uma população migra de sua origem para outro local, este leva consigo cultura, saberes, valores, crenças, vivências e experiências. No entanto, é preciso que o indivíduo viva em boas condições nesta nova moradia, educação, alimentação e emprego de boas qualidades, são requisitos de quem se desloca para outro lugar, neste caso, sendo relevante a qualificação necessária a atender as normas do mercado de trabalho. De fato estudar o êxodo rural é compreender as causas desse fenômeno social, como também caracterizar o perfil do migrantee porque a escassez de água no meio rural ocasiona esse fenômeno.

Os movimentos migratórios no Brasil, especificamente no nordeste, é um fator histórico, onde uma parcela da sociedade se desloca para outro local em busca de melhores condições de vida, a exemplo dos nordestinos que migram para o sudeste à procura de emprego. E não é de hoje que esse fenômeno acontece, como cita Araújo (2002):

Já no período de colonização e de povoamento constatava-se havia intensos deslocamentos no território, associado à forma como foi instalada a economia mercantil, e, na sequência, como se deu a acumulação capitalista.

O histórico de deslocamento para outros lugares mostra que a migração é causada não somente pela seca, as forças expansionistas e atracionistas são motivos primordiais que fazem o individuo pensar em sair de sua terra. Como salienta Ribemboim e Moreira (2008):

A migração do campo para cidade, particularmente para a "cidade grande" á metrópole, é, portanto, o resultado das forças de expulsão e atração.

Podemos definirforça de atração as ofertas que a cidade oferece sejam emprego, lazer, hospitais escolas, uma vez que nos centros urbanos é mais fácil encontrar bens de consumo. Sendo assim o motivo de jovens deslocarem para a área urbana, como ratifica Carvalho et al. (2009):

Um aspecto que vem sendo muito abordado ultimamente como sendo um fator para o êxodo rural é a falta de espaços que tragam cultura e lazer para o campo, pois são fatores de desconcentração e socialização que alivia o estresse causado pelo desgaste do dia-a-dia de trabalho no campo, assim, como a ansiedade e a depressão.

A ideia de se deslocar para outros lugares é motivo por vários sentidos, em maioria os jovens que vão morar na cidade em busca de cursar faculdade e se divertir. Segundo Carneiro (1998) "ausência de espaços de lazer é responsável, entre outros fatores, pela avaliação negativa do campo em ralação à cidade e pelo desejo de migração". 
Já as forças de expulsão buscam-se em fenômenos climáticos ou políticos, a exemplo, da escassez hídrica. Consoante Khan et al. (2008):

[...] a seca é um fator gerador de desemprego. Em busca da sobrevivência, os desempregados rurais se deslocam para as cidades, agravando seus problemas e alargando a fronteira do desemprego. Isto faz com que o desemprego rural causado pela seca seja, sem dúvida, um problema social sério e recorrente, responsável não só pelo êxodo rural, mas também pelo povoamento desorganizado das zonas urbanas, que não têm estrutura para abrigar um contingente tão grande de pessoas (os flagelados da seca). Como conseqüência, observa-se nestas zonas o aumento no número de mendigos, de favelados, doenças e violência."(Khan et al., 2005, p. 258)

A seca é um fenômeno que acarreta o aumento da população urbana, neste caso, a população rural migra para a cidade em busca de emprego, uma vez que com a seca, as plantações não frutificam, o rebanho não da leite. Ainda segundo Ribemboim e Moreira (2008):

Daí a dimensão de se conhecer melhor o perfil do migrante e as causas que o levaram a migrar, identificando-se os períodos de picos de migração, e fazendo uso destas informações parao estabelecimento de políticas públicas eficazes, podendo sugerir, inclusive, que, elevação de emprego e renda (mediante estímulos à produção rural intensiva em mão-de-obra ou o fortalecimento de redes urbanas de pequeno e médio porte) seria bem mais eficaz para o deslocamento rural integrado, do que as recorrentes políticas de combate às secas, tão ao gosto da politicagem local.

No nordeste muitas são as políticas de combate à seca e convivência com o semiárido que foram criadas com intuito de reter a população rural em seu meio e tornar a convivência com a seca a mais fácil possível, no entanto, muitas delas não conseguem dinamizar essa pratica, visto que o problema é a escassez hídrica é o fator que colabora coma migração.

Junior et al (2006) complementa:

Em maio as evidentes dificuldades que afligiram e afetam atualmente a agricultura familiar, principal categoria social rural atingida pela evacuação de seus constituintes para outras regiões, percebe-se que as politicas públicas não foram capazes e eficientes o suficiente para dar as condições necessárias para que estes autores pudessem continuar a permanecer no seu meio de origem.

É importante perceber que o meio do homem rural sobreviver no campo é a partir da agricultura familiar (cultivo do milho, feijão, melancia etc.), e sem essa ferramenta o individuo não tem possibilidade de sobreviver, principalmente na seca. Carvalho (2009) complementa "A agricultura familiar tem grande importância na redução do êxodo rural e no potencial de criar condições e oportunidade de trabalho e sobrevivência através de diversificados sistema de produção e utilização de recursos naturais".

\section{MATERIAIS E MÉTODOS}


O estudo foi desenvolvido no Centro de Ciências Humanas e Agrárias no Departamento de Agrárias e Exatas da Universidade Estadual da Paraíba no município de Catolé do Rocha/PB, (6²0’38”S; 3744’48”W) e 275 metros de altitude. O clima do município, de acordo com a classificação de Koppen, é do tipo BSW', ou seja, quente e seco do tipo estepe, com temperatura média mensal superior a $18^{\circ} \mathrm{C}$, durante todo o ano.

A pesquisa segue modelos metodológicos quantitativos e qualitativos e foi dividido em duas etapas, detalhado abaixo:

- $1^{\circ}$ etapa: Nesta etapa foi feito o levantamento bibliográfico sobre a temática, como também leituras criticas de artigo, livros e dissertações a fim de analisar a influencia da seca na vida popular rural de outras regiões;

- $2^{\circ}$ etapa: Foram feitas entrevistas com moradores do sitio cajueiro, para isso, foi aplicado um questionário semiestruturado.

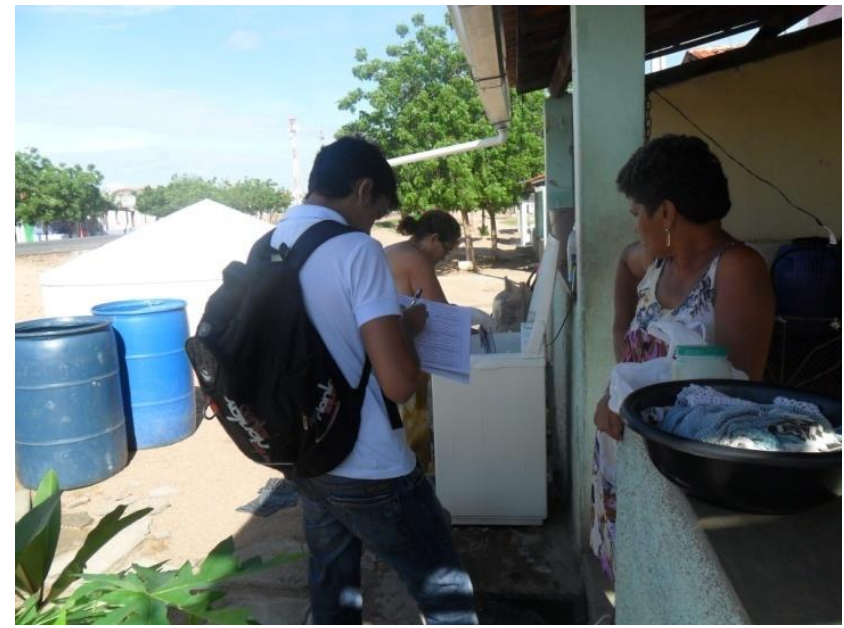

Figura 1: Entrevista no sítio Cajueiro, Catolé do Rocha - PB, 2013.

A priori, foram entrevistadas 37 famílias na zona rural (figura 1) onde foram abordados assuntos pessoais, econômicos, familiares, perspectivas para o futuro. Já o questionário tinha o objetivo de responder as seguintes perguntas:

- Qual o motivo de se migrar?

- Quantas famílias pensaram em morar na cidade?

- E qual o motivo de permanecer no campo?

A seguir foi feito o diagnóstico das entrevistas, como também as respostas das perguntas.

\section{RESULTADOS E DISCUSSÃO}




\section{Características do município de Catolé do Rocha}

O município, pertencente ao estado da Paraíba, segundo o IBGE tem população de 28.759 habitantes.

Nesta parte foi feita, de inicio, a caracterização das famílias entrevistadas e posteriormente os temas da análise são expostos separadamente. A principio são apresentados os dados socioeconômicos das famílias (profissão, arranjo familiar, renda, escolaridade) seguida dos relatos de experiência e condições observadas sobre os três temas de analises: 1) famílias que já pensaram em ir morar na cidade; 2) Qual o motivo de se pensar em ir morar na cidade; 3) Qual o motivo de permanecer no campo. Por fim, sequem os resultados e discussão sobre os dados obtidos no campo.

\section{Características das famílias entrevistadas}

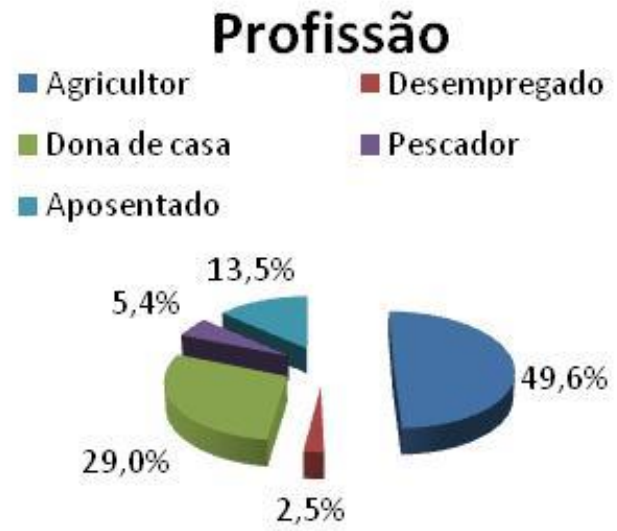

Figura 2: Profissão das famílias entrevistadas, Catolé do Rocha - PB, 2014.

Nota-se que a profissão das famílias é em maioria ligada à agricultura $(48,6 \%)$ (figura 2), muitas delas cultivam os alimentos nos muros e vendem nas feiras livres do município, as mulheres tomate, coentro, cebola, alface, pimentão entre outros, já os homens cuidam do rebanho e plantam milho, feijão, melancia, batata-doce.

De imediato, evidenciou-se que o trabalho no campo, na ótica da população rural, é um trabalho dinâmico além de ser produtivo e lucrativo. Carvalho et al (2009) notifica:

Esse foco para a agricultura familiar visa, além de melhorar a qualidade de vida na zona rural (diminuindo a pobreza, gerando desenvolvimento local, etc.), aumentar a produção de alimentos no pais fazendo com que a economia se torne mais concreta, já que a agricultura é um dos principais setores da economia e a população cresce 
cada vez mais, tornando o pais um pouco mais independente e cada vez mais forte no cenário mundial.

No entanto, pouco é investido na agricultura familiar, consoante Silva et al. (2006) há uma carência de politicas públicas voltadas ao campo e ao fortalecimento da agricultura familiar. Sendo assim uma forma de diminuir o êxodo rural, já que a população rural sobrevive disso:

\section{Arranjo familiar}

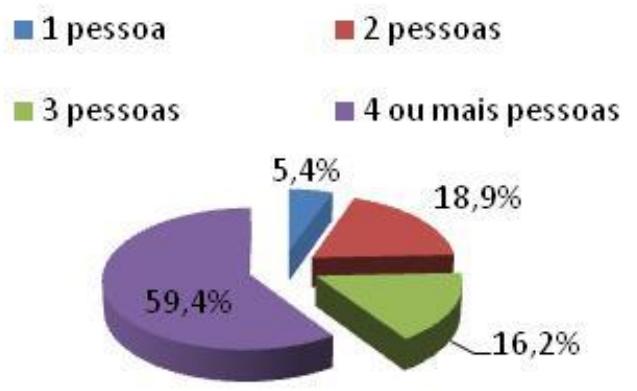

\section{Renda \\ - 1 a 2 salários}

- 3 ou mais salários

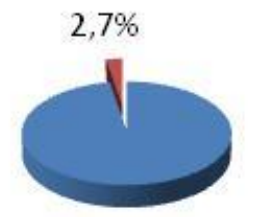

$97,2 \%$

Figura 3: Arranjo familiar e renda das famílias entrevistadas, Catolé do Rocha - PB, 2014.

As famílias entrevistadas em maioria (59,4\%) (figura 3) apresentam arranjos familiares com 4 ou mais pessoas por casa, onde são compostos por: pai, mãe, filhos e avó e/ou avô, percebe-se ainda que a renda não ultrapassa dois salários mínimos (97,2\%) (figura 3). As maiorias das entrevistadas trabalham na agricultura, os homens cuidam dos rebanhos e da lavoura, as mulheres donas de casa, se encarregam da atividade doméstica, os filhos estudam e as avós e/ou avó são aposentados.

Nota-se que sem a ajuda do chefe da família sem plantar e vender, seria difícil, sobreviver no meio rural, uma vez que, com apenas o salario da avó e/ou avô para uma família de 4 ou mais pessoas a família passaria fome.

Dai a possibilidade de migrar para a cidade. A necessidade de emprego e maior renda é um fator que obriga o homem migrar, como salienta Brito e Ribeiro (2010) "o trabalho é um fator de grande motivação para se migrar. É considerado possibilidade de prosperarão".

No entanto, quando estes migram, sem qualificação profissional, consoante Ribemboim e Moreira (2008) acabam trabalhando em comércio ambulante, camelôs e pequenos negócios familiares. 


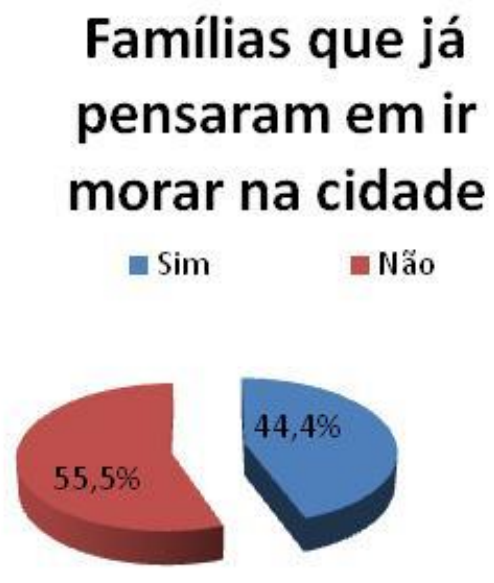

\section{Motivo de se pensar em ir morar na cidade \\ - Falta de água \\ - Falta de médico \\ Falta de ensino de qualidade}

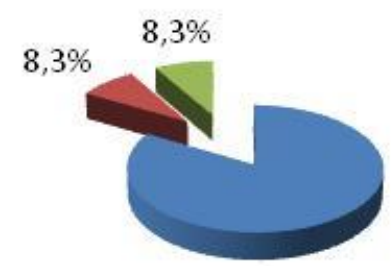

$83,3 \%$

Figura 4: Famílias que já pensam em ir morar na cidade e qual foi o motivo disso, Catolé do Rocha - PB, 2014.

Observa-se que das 37 famílias entrevistadas 55,5\% (figura 4) delas já pensaram em migrar para a cidade, e isso é motivado principalmente pela falta de água $(83,3 \%)$ que no meio rural está se tornando cada vez mais escassa. A questão de educação também é um fator que colabora no movimento migratório rural-urbano, neste caso, tendo que se deslocar para a cidade. Carvalho (2009) salienta que no meio rural as aulas são voltadas para a realidade urbana e isso faz com que o aluno perca o interesse em permanecer no campo.

\section{Motivo de permanecer no campo \\ - Porque se pode se plantar na zona rural \\ - Falta de condiçôes de pagar aluguel na cidade \\ Ealta de oportunidade de trabalho na cidade}

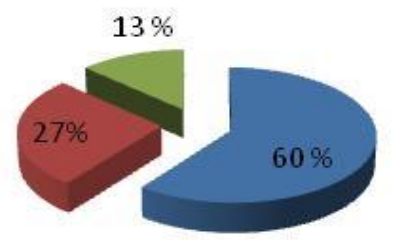

Figura 5: Motivo de permanecer no campo, Catolé do Rocha - PB, 2014. 
Mais uma vez a agricultura familiar é o fator que retém a população rural no seu meio. Das famílias entrevistadas (60\%) (figura 5) delas não migraram e nem pensaram em migrar para a cidade, visto que, na cidade não é o meio mais adequado a se plantar. Como cita Wanderley (2004) na zona rural as pessoas valorizam a questão da tranquilidade, liberdade e relacionamentos com os amigos, vizinhos e familiares que ali são construídos.

Deste modo a permanência no campo pode ser entendida como a união de diversos fatores que o homem põe na balança quando pensa em ir morar na cidade e os benefícios alcançados no campo.

\section{Escolaridade}

Analfabeto $\quad$ Ens. Fund. Incompleto
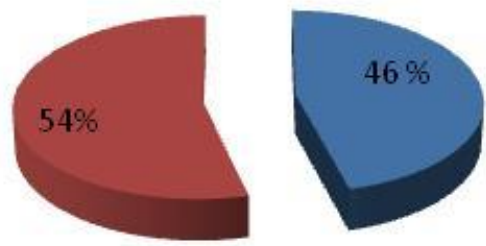

Figura 6: Escolaridade, Catolé do Rocha - PB, 2014.

A maioria das famílias entrevistadas 19 (54\%) (figura 6) tinha membro que não concluiu o ensino fundamental completo, além da taxa de analfabetismo também apresentar um número elevado (46\%) e com o ato migratório, essa parcela que se desloca, sem qualificação profissional, exerce empregos informais como camelos e ambulantes. Como ratifica Queiroz (2001) a educação de má qualidade tem ocasionado vários problemas, a exemplo do analfabetismo, evasão de alunos da escola, desvalorização de professores e escolas longe da realidade rural e assim estimulando o abandono ao campo. Neste caso, os alunos tendem a migrar para a cidade em busca de ensino de qualidade. 


\section{CONCLUSÃO}

Com o passar do tempo a população rural tem se atraído ao meio urbano por melhores condições de vida como saúde, educação, segurança e lazer, estas de boa qualidade são as forças atracionistas que fazem com que os ruralistas desloquem para a cidade, neste caso, aglomerando as periferias, uma vez que, sem emprego, sem condições de pagar aluguel num bairro nobre.

De outro lado as forças expulsionistas, que por nós pesquisadores, é a escassez hídrica, onde na zona rural de Catolé do Rocha, tem tornado difícil a vida do homem no campo, ocasionando assim o êxodo rural.

É preciso, sobretudo, criar estratégias de assegurar a convivência do homem rural em seu meio, de modo que o mesmo não precise se deslocar para outro local a procura de emprego, saúde, educação e água.

Em Catolé do Rocha, como em todo o nordeste, o movimento migratório não deve ser enxergado como decorrente da seca, mas resultante de conjunto de fatores, políticas públicas de abastecimento de água, ensino de qualidade, saúde de qualidade e acima de tudo medidas de melhoramento da agricultura familiar — fonte de renda do agricultor.

As condições de vida dos moradores da zona rural de Catolé do Rocha mostram que a ineficácia de programas e políticas públicas voltadas ao combate à seca têm favorecido a migração de muitas famílias para as cidades, uma vez que, não é só a falta de água que colaboradora nesse processo, a inviabilidade e a vulnerabilidade das técnicas de água dificultam ainda mais a vida do homem do campo.

É relevante a reformulação como também a adaptação de tais propostas a realidade semiárida, desse modo é possível solução desse problema da seca.

O sitio cajueiro como os outros sítios apresentam um déficit de água, onde muitas famílias carentes precisam abastecer as cisternas por carro-pipa, neste caso, comprometendo o orçamento familiar.

É preciso, sobretudo, estabelecer condições do homem do campo viver no meio rural, para que o mesmo não precise se deslocar para a cidade. 


\section{REFERÊNCIAS}

ALVES, E. Migração rural-urbana. Revista de Política agrícola. v. IV. n. 4, p. 15- 29, out/dez 1995.

MENEZES, I. G. de. Valorização do rural versus valorização do Camponês; desenvolvimento, trabalho e cidadania. Revista eletrônica temática. Out. 2008.

ARAÚJO, A. A. M. O êxodo rural dos trabalhadores rurais para cidades à luz de Lefebvre. Scripta Nova, Revista Eletrônica de Geografia y Ciências Sociales, Universidade de Barcelona, vol. VI, n. 199 (121), 2002. (ISSN: 1138-9788). Disponível em <HTTP:I|www.ub.es/geocrit/sn/sn119121.htm>. Acesso em 28/01//2015.

CEM - Centro de Estudos Migratórios. Migração no Brasil: o peregrinar de um povo sem terra. São Paulo: Paulinas, 1986.

SOUSA, E. G. de. Políticas públicas voltadas ao homem do campo - O Pronaf em Bananeiras - PB (Especialização) Universidade Federal da Paraíba, Bananeiras, 2011.

BRITO, G. S.; RIBEIRO, A. E. M. Migrações rurais e fluxos de conhecimento agroecológico: o caso de montes claros MG. Qualit@s Revista Eletrônica. V. 9, n. 2, p.5-14, 2010.

CARNEIRO, M. J. Ruralidade: novas entidades em construção. Estudos sociedade e Agricultura, n. 11, Rio de Janeiro: CPDA/UFRRJ, 1998.

CARNEIRO, D. M. et al. Perspectivas dos jovens rurais: Campo versus cidade. In: Congresso Saber: sociedade Brasileira de economia, administração e sociologia rural, 47., 2009, Porto Alegre. Resumos..., p. 1-14.

REBEMBOIM, J.; MOREIRA, F. G. L. O fenômeno da "chegada urbana" em contraponto ao do "êxodo rural". In: Encontro Nacional de estudos Populacionais, 16. , 2008, Caxambu. Resumos... p. 1-14.

JUNIOR, V. J. W. et al. Os novos arranjos do êxodo rural: a evasão temporária de jovens agricultores familiares gaúchos. In: Congresso do Saber, 36. , 2006, Fortaleza. Resumos... p. $1-11$.

SILVA, P. S; FILHO, E. T.D.; MARACAJÁ, P. B.; PEREIRA, T. F. C. Agricultura familiar: um estudo sobre a juventude rural no município de Serra do Mel-RN. Revista Verde (Mossoró-RN-Brasil) V. 1, n. 1, p. 54-66. Janeiro/ Junho de 2006.

WANDERLEY, Maria de Nazau; WANDERLEY, M. de N. B. (org.) Globalização e desenvolvimento Sustentável; São Paulo: Polis; Campinas, SP: Ceres - Centro de Estudos Rurais do IFCH- Unicamp, 2004. P. 61-74.

KHAN, A. S. et al. "Efeitos da Seca sobre a Produção, a renda e o emprego agrícola na microrregião geográfica de brejo santo e no Estado do Ceará". Revista Econômica do Nordeste, v. 36, n. 2, Fortaleza, p. 242-262. 